\title{
A Cross Sectional Study on Hypertension and Tobacco Consumption in the Rural Adult Population of Kamrup, Assam
}

\author{
Shaheen Akhtar Choudhury ${ }^{1}$, Jutika Ojah ${ }^{2}$ \\ $\mathrm{PGT}^{1}$, Department of Community Medicine, Gauhati Medical College and Hospital \\ Professor and $\mathrm{HOD}^{2}$, Department of Community Medicine, Gauhati Medical College and Hospital
}

\begin{abstract}
Introduction: Tobacco consumption is a major source of mortality and morbidity in India. Overwhelming evidence supports the conclusion that cigarette smoking causes various adverse cardiovascular events and acts synergistically with hypertension and dyslipidemia to increase the risk of coronary heart disease Prevalence of smokeless tobacco (ST) consumption in India is around $20 \%$. The prevalence of tobacco consumption in rural areas of Assam according to NFHS 4 among men and women 64\% and 20.3\%. The present study is conducted to assess the tobacco consumption association with hypertension among the rural adult population of Kamrup, Assam. Objectives: 1) To assess the prevalence of hypertension among the rural adult population of Kamrup district, Assam. 2) To assess the association of tobacco consumption with hypertension. Methodology: A community based cross sectional study was conducted in the rural area of Kamrup district, Assam for a Period of one year (August 2015- July 2016). Adults aged 30 years and above is included in the study after taking informed consent, who have no acute illness and who were not pregnant. Subjects were interviewed using pre designed pre tested proforma. A total of 870 respondents were interviewed from 12 randomly selected villages. Ethical clearance obtained from Institutional Ethics Committee. Data presented in the form of table, bar diagram \& pie diagram. Data analysis done by using INSTAT GRAPH PAD, and a p value of < 0.05 is taken as significant. Results: The study shows, majority, 252 (28.96\%) respondents were normotensive, followed by 240 (27.58\%) were pre hypertensives, and least number of respondents i.e 180 ( $20.68 \%$ ) were hypertensive with stage 2 . In the present study, $45.63 \%$ as tobacco non users and $54.37 \%$ as tobacco users. Among tobacco users, $17.93 \%$ were smokeless tobacco consumer, $19.43 \%$ were current smokers, $12.87 \%$ were ex- smokers and $4.14 \%$ were using mixed variety. Prevalence of hypertension was highest 53.25\% among the smokers, followed by $47.22 \%$ among the mixed variety users. The prevalence of hypertension was least, 39.29\%, among tobacco non users. The association of tobacco consumption and hypertension is statistically significant.
\end{abstract}

Keywords: Tobacco, Hypertension, Coronary heart disease, Kamrup, Assam

\section{Introduction}

Tobacco consumption is a major source of mortality and morbidity in India. According to estimates there are approximately 5 million deaths due to tobacco consumption annually which is expected to reach 10 million by 2025 . Currently over $20 \%$ of worldwide tobacco related mortality occurs in India $[1,2]$. In developing countries like India, tobacco consumption is mainly done in two forms: smoked tobacco products and smokeless tobacco. Most commonly used smokeless tobacco products include - tobacco pan masala, tobacco with lime, tobacco with pan and betel quid [3]. Prevalence of smokeless tobacco consumption in India is $20 \%$. It is significantly higher in males than in females ( $28 \%$ in males and $12 \%$ in females) and in rural population as compared to urban population [4]. Easy affordability, lesser cost and misconceptions regarding its useful health effects are important contributory factors for increased smokeless tobacco consumption.

Even if assessing systolic BP immediately after environmental smoking exposure may be difficult unless in experimental findings, one cannot deny its increase and, consequently, its interpretation as a marker of smoking exposure [5]. The acute effects of smokeless tobacco have been documented by increases of up to $21 \mathrm{~mm} \mathrm{Hg}$ in systolic blood pressure and $14 \mathrm{~mm} \mathrm{Hg}$ in diastolic blood pressure and by an average increase of 19 beats per minute in heart rate[6]. Cigarette smoking has been associated with acute insulin resistance. Although the mechanism is not entirely clear, it may be related to increased levels of nor epinephrine or other counter regulatory hormones, such as growth hormone or Cortisol. Eliasson et al[7] demonstrated that smokeless tobacco users had higher insulin levels than nonusers, suggesting a similar link between smokeless tobacco and insulin resistance

Overwhelming evidence supports the conclusion that cigarette smoking causes various adverse cardiovascular events and acts synergistically with hypertension and dyslipidemia to increase the risk of coronary heart disease. (Kannel ,1977) [8] Paradoxically, Berglund et. al (1975) ${ }^{108}$ concluded from their study that , BP levels among cigarette smokers were the same as or lower than those of nonsmokers. Cryer et. al ( 1976) [9] conclude from their study that, nicotine acts as an adrenergic agonist, mediating local and systemic catecholamine release and possibly the release of vasopressin. Tuomilehto et. al (1982)[10] concluded from their study that, smoking causes an acute increase in blood pressure (BP) and heart rate and has been found to be associated with malignant hypertension. Siegel et. al (1992)[11] reported from their study, the long-term effects of smokeless tobacco use on blood pressure levels differ depending on the user's age and level of physical activity and on the amount of smokeless tobacco used. In young, physically active baseball players, no increase in systolic blood pressure or heart rate was found. West man (1995)[12] reported from his study, the acute effects of smokeless tobacco have been documented by increases of up to $21 \mathrm{~mm} \mathrm{Hg}$ in systolic blood pressure and $14 \mathrm{~mm} \mathrm{Hg}$ in 


\section{International Journal of Science and Research (IJSR) \\ ISSN (Online): 2319-7064}

Index Copernicus Value (2015): 78.96 | Impact Factor (2015): 6.391

diastolic blood pressure and by an average increase of 19 beats per minute in heart rate. These effects are likely related to activation of the sympathetic nervous system.

Hazarika et.al. (2002) [13] repoted from their study, smokeless tobacco consumption in the form of khaini was found to be associated with hypertension in women.Similar finding was reported from the study by Gupta et .al (2007) [14] as well as from a study among western population by Hergens et.al. (2008). [15] The prevalence of tobacco consumption in rural areas of Assam according to NFHS 4 among men and women $64 \%$ and $20.3 \%$. The present study is conducted to assess the tobacco consumption association with hypertension among the rural adult population of Kamrup, Assam. The present study is conducted to assess the tobacco consumption association with hypertension among the rural adult population of Kamrup, Assam.

The present study was conducted with the following objectives:

1) To assess the prevalence of hypertension and tobacco consumption among the rural adult population of Kamrup district, Assam.

2) To assess tobacco consumption as a risk factor for hypertension.

\section{Materials and methods}

The present study is conducted as a community based cross sectional study, in the rural areas of Kamrup district, Assam for a period of one year (August 2015- July 2016). The study was conducted among adults aged 30 years and above. Sample size was calculated using the formula $\mathrm{n}=4 \mathrm{pq} / \mathrm{L}$, where $p=31.7 \%$ ( prevalence of HTN in eastern rural India, taken from the study done by Raghupathy et.al, Systematic review \& meta-analysis, published in the Journal of Hypertension ,June 2014), $q=100-p, \quad L=10 \%$ of $p$. The sample size is calculated to be 866 , which is rounded up to 870 .

Kamrup (Rural) district has a total of 13 PHCs, of which taking 50\%, 6 PHCs are randomly selected. 2 sub centers from each of 6 PHCs are selected randomly. This gives us a total of 12 sub centers, included in the study. From each sub center, 1 villages are randomly selected. To get a sample size of 870,73 respondents are randomly selected from each village.

Data collected by using pre-designed, pre-tested interview schedule followed by physical examination (using sphygmomanometer, stethoscope). Interviews were conducted by house to house visit. Pregnant women, acutely ill patients \& those who did not give consent for the study was excluded. Obtained from the Institutional Ethics Committee.

BP was measured using mercury column sphygmomanometer using standard technique in the sitting posture, with the back supported, leg uncrossed and after the subject had rested for at least 5 minutes .The BP is recorded in the right arm using cuff of standard size with instrument at the level of individual's heart. The cuff pressure was inflated $30 \mathrm{~mm} \mathrm{Hg}$ above the level at which radial pulse disappeared and deflated slowly at the rate of $2 \mathrm{~mm} \mathrm{Hg}$ per second and the reading recorded to the nearest $2 \mathrm{~mm}$. The first and fifth korotkoff sound were taken indicative of SBP and DBP respectively. Two readings were taken at 5 minutes interval and average of the two reading is taken as individual BP. If the difference between the two measurement is more than $5 \mathrm{~mm} \mathrm{Hg}$, additional reading is taken and the average of 3 reading is considered as individuals BP. Participants who had taken food, tea, coffee, alcohol or who had smoked or done any strenuous physical activity were made to rest for 30 minutes before recording the $\mathrm{BP}$.

According to JNC VIII th recommendation, systolic BP $>=$ $140 \mathrm{mmHg}$ or diastolic $\mathrm{BP}>=90 \mathrm{~mm} \mathrm{Hg}$ is taken as hypertensives.

In the present study hypertensives are defined as those person who fulfills the criteria of JNC VIII and those on hypertensive medication.

Data analysis done by using INSTAT GRAPH PAD, and a $\mathrm{p}$ value of $<0.05$ is taken as significant.

\section{Operational Definition for Tobacco Use}

Current smoker: A person who has smoked at least 100 cigarettes in his lifetime and has continued to smoke every day or some days in the last 30 days

Ex-smoker or former smoker: Defined as a person who has smoked more than a 100 cigarettes in his lifetime and who has not smoked for the last 12 months.

Tobacco chewing: Defined as a person who has consumed smokeless tobacco once a day or nearly every day in any form for the last 12 months

\section{Results}

The community based cross sectional study was conducted among rural adult population of Kamrup district, Assam. A total of 870 respondents were interviewed. Out of the total respondents, $31.72 \%$ were male and $68.28 \%$ were female. Majority of the respondents i.e $33.79 \%$ were in the age group 30- 39 years and least $>=60$ years i.e $6.20 \%$. Among the total respondents $45.63 \%$ were non users of tobacco and $54.37 \%$ were tobacco users. Of the total respondents , $32.3 \%$ were smokers, $17.93 \%$ were smokeless tobacco users and $4.14 \%$ were mixed variety users.

Table1: Distribution of respondents according to tobacco

\begin{tabular}{|c|c|c|}
\hline \multicolumn{3}{|c|}{ use. } \\
\hline Tobacco use & Frequency & Percentage \\
\hline Non users & 397 & 45.63 \\
\hline Users & 473 & 54.37 \\
\hline Total & 870 & 100 \\
\hline
\end{tabular}

Table 1, showing distribution of respondents according to tobacco use and table 2, showing distribution of respondents according to various forms of tobacco use. Table 3, showing distribution of respondents according to socio demographic status. 


\section{International Journal of Science and Research (IJSR) \\ ISSN (Online): 2319-7064 \\ Index Copernicus Value (2015): 78.96 | Impact Factor (2015): 6.391}

Among the total respondents of tobacco users $(n=473)$, $46.09 \%$ were male and $53.91 \%$ were female and the difference is found to be statistically significant. $(\mathrm{p}<0.0001)$. Among the total respondents using tobacco, highest percentage of users were among the age group 3039 yrs i.e $43.55 \%, 40-49$ yrs $=40.59 \%, 50-59$ yrs $=10.99 \%$, $>=60 \mathrm{yrs}=4.86 \%$. Age and tobacco use is found to be significantly associated statistically $(\mathrm{p}<0.0001)$.

Table 2: Distribution of respondents according to various forms of tobacco consumption.

\begin{tabular}{|l|l|l|}
\hline \multicolumn{1}{|c|}{ Tobacco use } & \multicolumn{1}{|c|}{$\begin{array}{c}\text { No. of } \\
\text { respondents }\end{array}$} & $\begin{array}{c}\text { Percentage } \\
(\%)\end{array}$ \\
\hline 1)Non users & 397 & 45.63 \\
\hline 2) Smokeless tobacco uses & 156 & 17.93 \\
\hline 3) Smokers & & \\
\hline Current smokers & 169 & 19.43 \\
\hline Ex- smokers & 112 & 12.87 \\
\hline 4)Mixed variety users & 36 & 4.14 \\
\hline Total & 870 & 100 \\
\hline
\end{tabular}

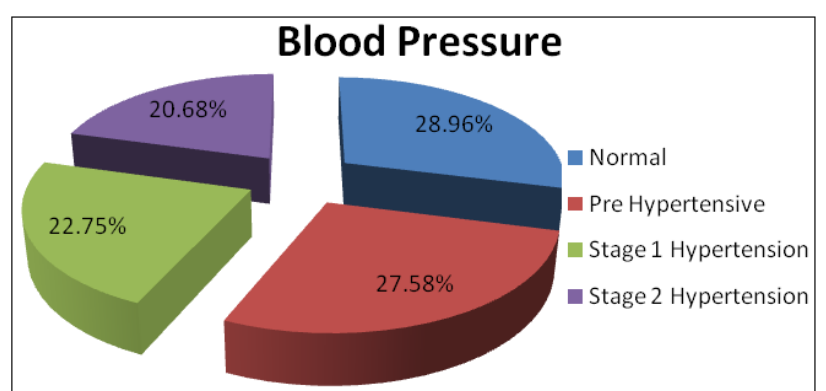

Figure 1: Distribution of respondents according to the blood pressure status
Table 3: Distribution of respondents according to socio demographic variables.

\begin{tabular}{|c|l|l|}
\hline Socio - demographic variables & $\begin{array}{c}\text { No. of } \\
\text { respondents, } \\
\text { n=870 }\end{array}$ & $\begin{array}{c}\text { Percentage } \\
\text { (\%) }\end{array}$ \\
\hline Age: 30-39 yrs & 294 & 33.79 \\
40- 49 yrs & 264 & 30.34 \\
$50-50$ yrs & 258 & 29.65 \\
>= 60 yrs & 54 & 6.20 \\
\hline Gender: Male & 276 & 31.72 \\
Female & 594 & 68.28 \\
\hline Religion: Hindu & 720 & 82.76 \\
Islam & 102 & 11.72 \\
Christianity & 48 & 5.52 \\
\hline Jype of family: Nuclear & 526 & 60.46 \\
Joint & 344 & 39.54 \\
\hline Education: Illiterate & 282 & 32.41 \\
Primary school & 239 & 27.47 \\
High school & 145 & 16.67 \\
HSLC & 85 & 9.77 \\
HS passed & 74 & 8.51 \\
Graduate and above & 45 & 5.17 \\
\hline \multicolumn{2}{|r|}{}
\end{tabular}

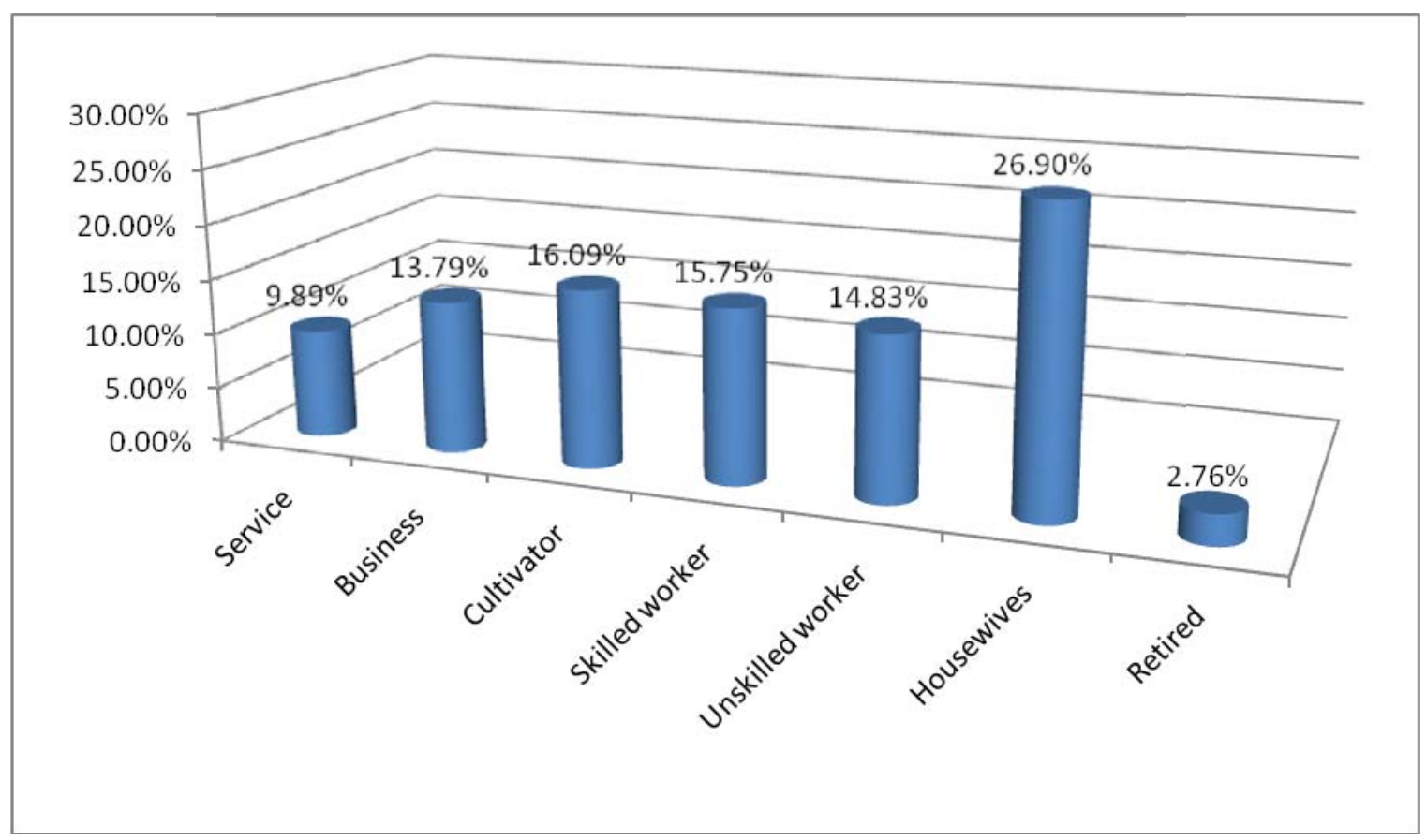

Figure 2: Distribution of respondents according to occupation 


\section{International Journal of Science and Research (IJSR) \\ ISSN (Online): 2319-7064}

Index Copernicus Value (2015): 78.96 | Impact Factor (2015): 6.391

Table 4: Distribution of respondents according to tobacco use and hypertension

\begin{tabular}{|l|c|c|c|c|c|c|}
\hline \multirow{2}{*}{ Tobacco use } & \multicolumn{2}{|c|}{ Hypertensives } & \multicolumn{2}{|c|}{$\begin{array}{c}\text { Non } \\
\text { Hypetensives }\end{array}$} & Total & $\begin{array}{c}\text { P } \\
\text { value }\end{array}$ \\
\cline { 2 - 6 } & No. & $\%$ & No. & $\%$ & No. & $<0.05$ \\
\cline { 1 - 6 } $\begin{array}{l}\text { 1) Tobacco non } \\
\text { users }\end{array}$ & 156 & 39.29 & 241 & 60.71 & 397 & \\
\cline { 1 - 5 } $\begin{array}{l}\text { 2) Smokeless } \\
\text { tobacco users }\end{array}$ & 66 & 42.31 & 90 & 57.69 & 156 & \\
\hline 3) Smokers & & & & & \\
\hline Current smokers & 90 & 53.25 & 79 & 46.75 & 169 \\
\hline Ex- smokers & 49 & 43.75 & 63 & 56.25 & 112 \\
\hline 4) Mixed Variety & 17 & 47.22 & 19 & 52.78 & 36 \\
\hline \multicolumn{1}{|c|}{ Total } & 378 & 43.45 & 492 & 56.55 & 870 & \\
\hline
\end{tabular}

Row wise percentage

Among the total respondents, hypertensives were $43.45 \%$ of the respondents. Fig 1 is showing the distribution of respondents according to their blood pressure status. In the socio demographic profile, majority of respondents were living in nuclear family $(60.46 \%)$, Maximum of the respondents belong to hindu religion i.e $82.76 \%$. Majority of respondents were illiterate i.e $32.41 \%$. Fig 2 showing distribution of respondents according to occupation, where majority $26.9 \%$ of the respondents were house wives. Table 4 , is showing the distribution of respondents according to hypertension and tobacco use. The prevalence of hypertension is highest among the smokers i.e 53.25\%. Tobacco consumption is found to be statistically associated with hypertension.

\section{Discussion}

The present study concludes that, out of the total respondents , $45.63 \%$ were tobacco non users and $54.37 \%$ as tobacco users. Among tobacco users, 17.93\% were smokeless tobacco consumer, $19.43 \%$ were current smokers, $12.87 \%$ were ex- smokers and $4.14 \%$ were using mixed variety. Prevalence of hypertension was highest $53.25 \%$ among the smokers, followed by $47.22 \%$ among the mixed variety users. The prevalence of hypertension was least, $39.29 \%$, among tobacco non users. The association of tobacco consumption and hypertension is statistically significant. This findings correlates with the study by Hazarika N C et. al (2004)[16] which reported prevalence of hypertension as $34.84 \%$ among smokers and $29.26 \%$ among chewers among the respondents of 30 years and above. Another study by Ambarish Pandey et. al (2009) [17] reported, prevalence of exclusive ST users as $21 \%$ while $19.4 \%$ consumed both forms and $26.6 \%$ did not take any form of tobacco. The prevalence of diastolic hypertension was significantly higher in exclusive ST users as compared to non users $(40.9 \%, 22.9 \%$; p value $=0.01)$. Prevalence of systolic hypertension was higher in exclusive ST users too though this was not statistically significant $(43 \%, 36.4 \% ; \mathrm{p}$ value $=0.39$. $)$. Another study by Mandal $\mathrm{P}$ $\mathrm{K}$ et. al (2010)[18] reported prevalence of hypertension as $56.8 \%$ among tobacco users compared to $10.5 \%$ among non users. The difference was found to be statistically significant.
It was a well established fact that tobacco consumption in any of the manner increases systolic and diastolic blood pressures, leading to circulatory defects. It is usually presumed that cigarette smokers are more affected than smokeless tobacco users. But studies have clearly said that tobacco in form has equal harmful effects $[19,20]$.

Several possible mechanisms have been proposed such as an imbalance of the central nervous system, impairment of the baroreceptors, enhanced sympathetic activity, stimulation of the renin-angiotensin-aldosterone system, increased Cortisol levels, increased vascular reactivity due to increase in intracellular calcium levels, stimulation of the endothelium to release vasoconstrictors and loss of relaxation due to inflammation and oxidative injury of the endothelium leading to inhibition of endothelium-dependent nitric oxide production. Loss of relaxation due to inflammation and oxidative injury of the endothelium by Angiotensin II leading to inhibition of endothelium-dependent nitric oxide production is the major contributors of the alcohol-induced hypertension [21]

\section{Conclusion}

The present study clearly depicts the health status of the rural adult population, in terms of non communicable disease. Hypertension being one of the common non communicable diseases is not only afflicting the urban population but also the rural population. Tobacco consumption is an established risk factor for hypertension. Tobacco consumption is in increasing trend in rural areas especially in the productive age group. The present study highlights the increasing trend of tobacco use in the rural areas. The prevalence of hypertension is significantly higher among those with tobacco consumption. Even though government is laying many regulations like label ling tobacco products as harmful and increasing the tax on them, complete ban on tobacco products are required to save the rural population who are the backbone of Indian agricultural Industry. Increased level of awareness generation is necessary to develop among the rural population to adopt healthy life style and to go for regular health check up.

\section{Limitation}

The present study was a community based cross sectional study , but appropriate design for this study should have been cross sectional design. Due to feasibility constraints cross sectional design is selected for the study. Due to time constraints various other factors cannot measured.

\section{References}

[1] World Health Organization: Making a Difference. In World Health Report World Health Organization: Geneva; 1999.

[2] Gupta PC, Ball K: India: Tobacco Tragedy. Lancet 1990:335-595.

[3] Gupta PC, Ray CS: Smokeless tobacco and health in India andSouth Asia. Respirology 2003, 8(4):419-31.

[4] Rani M, Bonu S, Jha P, Nguyen SN, Jamjoum L: Tobacco use inIndia: prevalence and predictors of 


\section{International Journal of Science and Research (IJSR) \\ ISSN (Online): 2319-7064 \\ Index Copernicus Value (2015): 78.96 | Impact Factor (2015): 6.391}

smoking and chewing in a national cross sectional household survey. Tob Control 2003, 12(4):e4.

[5] Mayer EJ, Quesenberry CP Jr, Friedman GD and Selby JV: Alcohol consumption and insulin concentrations: role for insulin in associations of alcohol intake with high-density lipoprotein cholesterol and triglycerides. Circulation 1993; 88: 2190-2197.

[6] Eliasson M, Lundblad D, Hagg E. Cardiovascular risk factors in young snuff-users and cigarette smokers. $J$ Intern Med. 1991; 23017- 22.

[7] Facchini FS, Chen Y-DI, Reaven GM: Light-tomoderate alcohol intake is associated with enhanced insulin sensitivity. Diabetes Care 1994; 17:115-119.

[8] Kannel WB. Importance of hypertension as a risk factor in cardiovascular disease. In: Hypertension: Pathopsychology and Treatment. New York, NY: McGraw-Hill; 1977: p 888-910.

[9] Cryer PE, Haymond MW, Santiago JV, Shah SD. Norepinephrine and epinephrine release and adrenergic mediation of smoking-associated hemodynamic and metabolic events. $N$ Engl J Med. 1976; (295) : p 573577.

[10] Tuomilehto J, Elo J, Nissmen A. Smoking among patients with malignant hypertension. BMJ. 1982;(1) $: p$ 1086- 90.

[11] Siegel DBenowitz NErnster VLGrady DGHauck WW Smokeless tobacco, cardiovascular risk factors, and nicotine and cotinine levels in professional baseball players. Am J Public Health. 1992;(82) ; p 417- 421

[12] Westman E Does smokeless tobacco cause hypertension? South Med J. 1995; (88); p 716- 720

[13] Hazarika NC, Biswas D, Narain K, Kalita HC, Mahanta J: Hypertension and its risk factors in tea garden workers of Assam. Natl Med J India , 2002, (15) :p 63-8.

[14] Gupta BK, Kaushik A, Panwar RB, Chaddha VS, Nayak KC, Singh VB, Gupta R, Raja S: Cardiovascular risk factors in tobacco-chewers:a controlled study. J Assoc Physicians India , 2007, (55): p 27-31.

[15] Hergens MP, Lambe M, Pershagen G: W. Ye, , Risk of hypertension in sweedish male snuff users: a prospective study. J Intern Med 2008, 264(2): p 187-94.

[16] Hazarika NC, Narain K, Biswas D, Kalita HC, Mahanta $\mathbf{J}$ - Hypertension in the native rural population of Assam. Natl. Med. J India, 2004; (17) : p 300 -304

[17] Pandey, Patni N , Sasmit Sarangi, Mansher Singh, Kartavya Sharma, Ananth $K$ Vellimana and Somdutta Patra et. al. Association of exclusive smokeless tobacco consumption with hypertension in an adult male rural population of India , Tobacco Induced Disease; November 2009 ,5(15), p: 1 - 5.

[18] Mandal P K, Sinha Roy A K, Chatterjee C, Mallik S, Manna N, Sardar J C, Chakrabarty D, Sau M. Burden of hypertension and its risk factors in an urban community of India : Are we aware and concerned ? Sudanese Journal of Public Health, July 2010; 3 (5) , p 130-135.

[19]IARC Monographs on the Evaluation of Carcinogenic Risks to Humans. IARC; 2002. Tobacco Smoke and Involuntary Smoking; p. 83.

[20] Yuen ST, Gogo AR Jr, Luk IS, Cho CH, Ho JC, Loh TT. The effect of nicotine and its interaction with carbon tetrachloride in the rat liver. Pharmacol Toxicol 1995; 77: 225-230.

[21] Kazim Husain, Rais A Ansari, and Leon Ferder, Alcohol-induced hypertension: Mechanism and prevention, World J Cardiol. 2014 May 26; 6(5): 245252. 